\title{
Corrigendum
}

\section{Food insecurity patterns before and after initial receipt of Supplemental Security Income - CORRIGENDUM}

\author{
Rajan A Sonik, Susan L Parish and Monika Mitra
}

Doi:10.1017/S1368980019000570, Published online by Cambridge University Press, 27 March 2019

\section{Original text and correction:}

ORIGINAL TEXT (page 1912, Acknowledgements)

Financial support: This work was supported by a Social Security Administration Disability Determination Process Small Grant Program grant and a Heller Annual Fund grant. The funders had no role in the design, analysis or writing of this article.

\section{CORRECTION}

The authors omitted one of their funders in the Acknowledgements section; please find the updated statement below:

Financial support: This work was supported by a Social Security Administration Disability Determination Process Small Grant Program grant and a Heller Annual Fund grant. The funders had no role in the design, analysis or writing of this article. This project was supported by grant number R03HS026317 from the Agency for Healthcare Research and Quality. The content is solely the responsibility of the authors and does not necessarily represent the official views of the Agency for Healthcare Research and Quality.

\section{Reference}

Sonik R, Parish S \& Mitra M (2019) Food insecurity patterns before and after initial receipt of Supplemental Security Income. Public Health Nutrition, 22(10), 1909-1913. doi:10.1017/S1368980019000570 